\title{
RAĐANJE U POZNIM GODINAMA METODAMA ASISTIRANIH REPRODUKTIVNIH TEHNOLOGIJA
}

\author{
Nebojša Zečević1,2
}

\author{
${ }^{1}$ Medicinski fakultet Univerziteta u Beogradu \\ ${ }^{2}$ Ginekološko-akušerska klinika Narodni front, Beograd
}

Jedan od najjačih nagona u svakom ljudskom, ali i animalnom biću na planeti je pored nagona za opstankom i nagon za reprodukcijom, produženjem vrste i replikacijom sopstvenih gena. Kod ljudske vrste je možda ne tako izražen na prvi pogled, ali i jednako prisutan. Svaki čovek ima nagon za reprodukcijom, ostavljanjem potomaka, obzirom na naš ograničen vek na planeti i u vremenu.

U poređenju sa životinskim vrstama, ljudska vrsta ne spada u jako plodne i reproduktibilne, jer trudnoća kod žena traje oko 280 dana (10 lumarnih ili 9 kalendarskih meseci), ljudska materica je projektovana za najčešće samo jedan plod, ređe 2 ili više, a uz povećanje mase ljudskog mozga, zbog uspravnog hoda, karlica žena je postala dosta uska za prolaz ploda prilikom porođaja. Za razliku od životinja, gde novorođenče uglavnom već posle nekoliko sati nakon rođenja staje na noge, kreće se, vidi, čuje, prati majku, sisa, a može i bežati i izbegavati opasnost, novorođenče kod ljudi se rađa prilično nezrelo, prohoda tek posle godinu dana od rođenja i nesposobno za samostalni život van materice barem još nekoliko godina, te je odvajanje od roditelja znatno kasnije.

Fiziološki najpovoljniji period za rađenje deteta je od 20 - 25. godine, jer je tada žena potpuno formirana za ostvarivanje i iznošenje trudnoće i rađanje. Međutim, u urbanim mestima, gde se pod uticajem sredine, obrazovanje i napredovanje u karijeri stavljaju ispred roditeljstva, žene se najčešće odlučuju za trudnoću nešto kasnije između 25 - 30. godine, dok u ruralnim sredinama, gde je uticaj ovih socijalnih faktora znatno slabiji, ovaj period nastupa u proseku 6 - 8 godina ranije. Ipak, poslednjih godina, pa čak i decenija, može se primetiti trend porasta broja žena koje se odlučuju za rađanje u kasnijim godinama, posle 30-te, a ne tako retko i posle 40-te godine života [1].

U literaturi se navode brojni socijalni razlozi sve većeg porasta broja starijih prvorotki: povećanje broja visokoobrazovanih žena, davanje prednosti karijeri nad roditeljstvom, finansijska nesigurnost i nezaposlenost, problem u pronalaženju adekvatnog partnera, kao i veći broj partnera pre braka, sa posledničnim češćim oboljenjavanje genitalnih organa i slično [2-7]. Takođe, česta upotreba savremenih metoda kontracepcije mogla bi da doprinese odlaganju planiranja porodice [8]. Paradoksalno reproduktivna sposobnost čiji je početak kod devojčica markiran prvom menstruacijom odnosno menarhom, kod urbanih devojčica nastaje u proseku 1,5 - 2 godine ranije (u proseku između 10 - 11. godine u gradu, a u ruralnim sredinama između 11-12,5 godine) $[9,10]$. Time se mozda može objasniti i veći broj estrogen zavisnih tumora kod gradske populacije žena i odnosu na ruralnu, jer su duži vremenski period pre rađanja izložene dejstvu ovog hormona [11].

Sa druge strane, ono što je ostalo isto tokom vremena, jeste činjenica da sposobnost oplodnje kod žena opada sa godinama. Lošiji kvalitet oocita svakako je značajan faktor koji doprinosi smanjenju potencijala za oplodnju [12]. Takođe, i sposobnost endometrijuma za implantaciju se smanjuje tokom godina, međutim ovaj efekat se može korigovati suplementacijom progesterona, što je naročitno značajno upravo kod starijih žena koje su se odlučile na trudnoću, kao i kod žena u menopauzi $[13,14]$. U ostale faktore spadaju plodnost partnera, učestalost koitusa, pojava prevremene menopauze, endometrioza, inflamatorne bolesti, anovulatorni ciklusi, sekvele nakon primene metoda kontracepcije, psihološki faktori [1].

Starost majke veća od 35 godina, ranije je bila definicija uznapredovalih godina i visokorizične trudnoće, što se iz gore navedenih razloga promenilo, te je sada granica pomerena na 40 godina, kao cut-off za praćenje visokorizične trudnoće $[15,16]$. Ipak, veliki broj žena nije upoznat sa potencijalnim faktorima rizika koji su povezani sa odlaganjem trudnoće. I u normalnoj, fiziološkoj trudnoći se dešavaju brojne hemodinamske promene koje dovode do povećanja udarnog volumena za čak $40 \%$, sa daljom tendencijom povećanja tokom druge faze porođaja; promene $\mathrm{u}$ funkcionisanju bubrega u vidu povećanja protoka krvi kroz bubrege i glomerularne filtracije; promene u respiratornom sistemu i hormonske promene, koje sveukupno predstavalju izvesan stres, čak i za telo mladih žena [17]. Sa druge strane, kod žena starijih od 45 godina prevalenca hipertenzije, oboljenja srca, hronične plućne bolesti, oboljenja bubrega i dijabetesa dramatično je povećana [18], kao i mortalitet usled različitih neoplazmi i kardiovaskularnih oboljenja [19]. Takođe, učestalost abortusa povećava se sa starošću majke, a kao glavni razlozi navode se hromozomske aberacije i hipoperfuzija placente [20]. Paralelno sa tim, kvalitet sperme se smanjuje kod starijih muškaraca, uglavnom na račun motiliteta i morfologije, dok se njihov broj ne smanjuje značajno [21]. Pored toga, 
trudnoća u starijim godinama povezana je sa većom incidencom udružene mole hydatiose, mioma uterusa i infekcija urinarnog trakta [22-24]. Zbog svega ovoga, trudnoća u starijim godinama udružena je sa rizicima po zdravlje majke, te se trudnoća u uznapredovalim godinama dovodi u vezu sa većom učestalošću hronične hipertenzije, preeklampsije, eklampsije, gestacijskim dijabetesom i prevremenim porođajem [25]. Starost trudnice predstavlja i faktor rizika za operativno završavanje trudnoće - carski rez [26]. Ipak iako je stanje posle vantelesne oplodnje kod ove grupe pacijenata najdominatnija indikacija za carski rez, u svetu se sve više daju preporuke da se prilikom završavanja ovih trudnoća vodimo pre svega akušerskim indikacijama, a ne kako je trudnoća ostvarena i godinama pacijetkinje. Takve preporuke bi pre svega trebale dovesti do većeg broja vaginalnih porođaja kod starijih žena koje su trudnoću ostvarile procesom vantelesne oplodnje, a time bi se i smanjile sve vrste komlikacija trudnoće vezanih za samu operaciju carskog reza [27]. Na kraju, smrtnost majki koje svoju trudnoću nose u kasnijim godinama života je takođe veća, a kao glavni razlozi navode se toksikemija, placenta previa, postpartalna hemoragija, emobolija amnionskom tečnošću, i ostale komplikacije u puerperijumu [28].

Sa druge strane, rizici po neonatuse rođenih iz ovakvih trudnoća već godinama su predmet rasprave. Istraživanju ukazuju da se iz trudnoća starijih majki češće rađaju prevremeno rođena deca, niže telesne mase na rođenju, ali i da je povećana incidenca kongenitalnih anomalija (smatra se da je to prevashodno zbog starijih gameti), tortikolisa, perinatalne asfikcije i perinatalne smrtnosti [24, 29-31].

Bez obzira na sve, novi trend kasnijeg odlučivanja na potomstvo, a sa druge strane i napredak u lečenju neplodnosti, doveli su do velike potražnje za asistiranim reproduktivnim tehnologijama (ART) [32]. Sve od prve „bebe iz epruvete” (engl. Test-tube baby) do danas prati se uticaj asistiranih reproduktivnih tehnologija na zdravlje majke i deteta [33]. Razvojem novih tehnologija ponuđena su nova rešenja u tretmanu infertiliteta, a otvorena je i mogućnost za rađenje u poznim godima, čak i nakon menopauze (prestanka menstruacije). ART koje su danas široko u upotrebi su: in vitro fertilizacija i embriotransfer (IVF/ET), intracitoplazmatska injekcija spermatozoida (ICSI), transfer zamrznotog embriona (FET). [34].

Ukoliko žena još uvek nije ušla u menopauzu, određivanjem hormonskog statusa, pre svega merenjem AMH (Antimilerovog hormona), FSH (folikulostimulirajućeg hormona), kao i nivoa inhibina, procenjuje ovarijalna rezerva, odnosno zaliha zrelih oocita koje bi potencijalno mogle biti oplođene. Ipak, procentat uspeha vantelesne oplodnje sa sopstvenim (nedonorskim) jajnim ćelijama znatno opada sa godinama života žene,

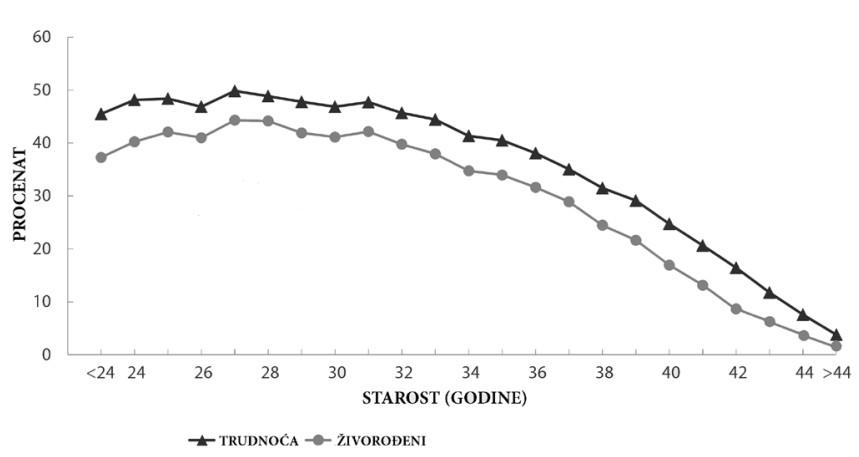

Grafik 1. Procenat ART ciklusa sa nedonorskim jajnim ćelijama ili embrionima koji su rezultirali trudnoćom, odnosno živorođenošću u odnosu na godine žena (Nacionalni registar CDC-ja za 2013. godinu) [35].

te je u 45. godini prosečna šansa za ostvarenje trudnoće procesom vantelesne oplodnje samo oko 2\% (Grafik 1). Stoga se, ukoliko su vrednosti ovih hormona niže, ali i kod žena starijih od 45. godina koje planiraju trudnoću, savetuje se donacija jajne ćelije, a zatim postupak veštačke oplodnje. Donacija jajne ćelije znači da se vantelesna oplodnja radi sa spermom supruga i jajnom ćelijom donatorke - po pravilu mlađe žene, koja ispunjava sve zdravstene, zakonske i druge uslove za donacijom. Već odavno u svetu postoje banke jajnih ćelija, sperme, pa čak i gotovih embriona.

Materica se, čak i nakon menopauze hormoskim preparatima može pripremiti za implementaciju, pa se, nakon 2. (ili 5. dana, u stadijumu blastociste) od oplodnje, metodom embriotransfera u nju ubacuje oplođena donirana jajna ćelija, te se trudnoća može ostvariti i izneti. Međutim i procenat uspešnosti emriotransfera takođe opada u odnosu na starost majki (Grafik 2).

Naša zemlja na žalost nema još uvek zakonske uslove za veštačku oplodnju sa jajnim ćelijama ili spermom donatora, iako su oni već godinama u pripremi,

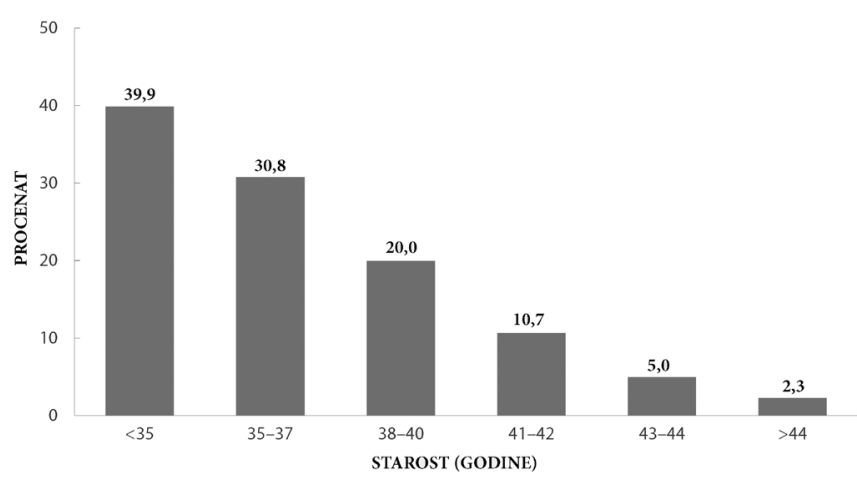

Grafik 2. Procenat uspešnosti implantacije nakon embriotransfera oplođenih sopstvenih jajnih ćelija u zavisnosti od godina majke (Nacionalni registar CDC-ja za 2013. godinu) [36]. 
te se te procedure rade u nekim inostranim centrima. U drugim zemljama, pre svega Zapadne Evrope, ali i Češkoj, Slovačkoj, Grčkoj, postoje zakoni koji vrlo uspešno regulišu ovu oblast, te su se vremenom razvile i banke jajnih ćelija, sperme i embriona. To znači da se parovima koji iz bilo kog razloga, zdravstvenog, ali i socijalnog, koji ne mogu da ostvare trudnoću prirodnim putem, pruža mogućnost da iz banke ćelija zatraže i dobiju odgovarajućeg donora jajnih ćelija, sperme, pa čak i embriona.

$\mathrm{Na}$ primer, par gde žena ima preko 40 godina i smanjenu ovarijalnu rezervu, a muškarac, na primer, ima azoospermiju (nedostatak vitalnih spermatozoida u spermi) ima šansu do ostvari trudnoću donacijom embriona iz banke ćelija. Tada se nakon pripreme materice žene adekvatnom hormonskom stimulacijom endometrijuma, vrši embriotrasfer unapred pripremljenim embrionima - donora. Genetski, naravno, takav par dobija decu bez sopstvenog genetskog materijala, ali ta žena će izneti tu trudnoću do temina porođaja, roditi to dete i naravno odgajiti ga i vaspitati zajedno sa suprugom prema sopstvenim vrednostima. Ovakav vid reprodukcije svakako ima prednosti, bez obzira na godine žene, u odnosu na surogat majku, jer se instinkt roditeljstva javlja još pre rođenja i to kod oba roditelja u toku trudnoće, a posebno tokom porođaja. Naravno, ovde se mogu razmatrati i druga filozofska, moralna, etička i socijalna pitanja materinstva i uopšte roditeljstva, kao na primer da li je majka ona koja da genetski materijal ili osoba koja iznese trudnoću, rodi i zajedno sa svojim suprugom vaspitava i odgaja dete.

Bez obzira na nedostatak zakonskih uslova, poslednjih godina zapanjući je rast trudnoća i porođaja ostvarenih posle veštačke oplodnje nakon 40 -te, 45-te čak i posle 50-te godine života. Samo u periodu od 2008-2013. na GAK Narodni Front porodile su se 224 žene starije od 40 godina koje su zatrudene nekom od metoda ART-a. Ono što svakako zavrednjuje pažnju je porast broja takvih žena tokom pomenutog perioda - 2008. porodilo se 11, a 2013. godine taj broj bio je 64. Procentualna distribucija ovih pacijentkinja po kalendarskim godnama data je $\mathrm{u}$ Grafiku 3.

Najstarija žena koju smo porodili na klinici imala je 59 godina. Kod svih je uglavnom urađen carski rez, i sve su trudnoću ostvarile metodom veštačke oplodnje (ART) i posle dugogodišnjeg lečenja steriliteta.

Ono što svakako poziva na oprez je činjenica da se kod ove populacije žena znatno češće javljaju komplikacije trudnoće u smislu i fetalnih i maternalnih ishoda. Naime, i u popupaciji neonatusa rođenih na GAK Narodni Front u periodu od 2008-2013. godine znatno češći broj pobačaja, pojave hipertenzije i dijabetesa kod majki, ali i rađanje dece manje telesne mase, sa makrozomijom, respiratornim distres sindromom, tortikolisom i neo-

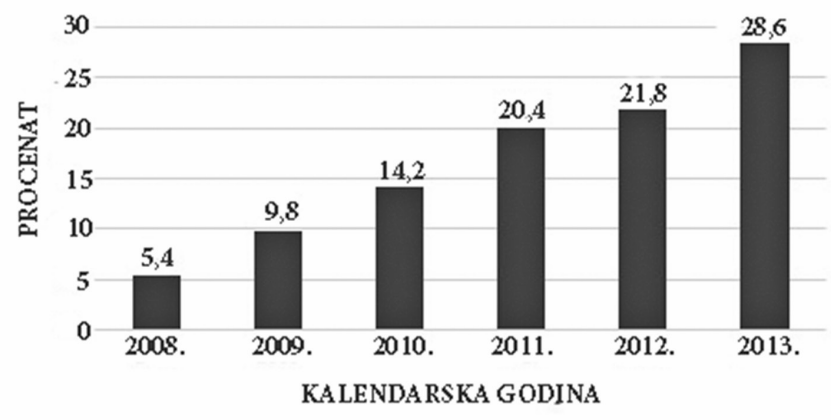

Grafik 3. Žene starije od 40 godina koje su zatrudnele metodama ART-a na GAK Narodni Front u periodu od januara 2008. do decembra 2013. godine (224 žene) - procentualna distribucija po kalendarskim godinama.

natalnim ikterusom kod grupe trudnica uznapredovale starosti u odnosu na grupu žena koje rađaju pre 40-te godine života (Grafik 4).

Međutim, sterilitet nije jedini razlog zbog kojeg su žene želele da ostanu trudne u uznapredovalom životnom dobu. Naime, određeni broj žena napredak u tehnologijama ART koristilo je i za zadovoljenje bračnih i ličnih potreba, iako su već realizovane kao roditelji. $\mathrm{Na}$ primer, pre nekoliko meseci smo na klinici imali pacijetkinju staru 51 godinu, koja u 33 nedelji trudnoće nosi blizance, kod koje je trudnoća ostvarena procesom vantelesne oplodnje, donacijom jajnih ćelija. IVF tretman i donacija oocita ostvarena je u jednom inostranom centru za vantelesnu oplodnju. Ono što je kod te žene neobično je što ima već dvoje odrale dece ( 24 i 21 godinu), a koja se drugi put udala sa svojih 47 godina. Posle samo godinu dana je izgubila menstruaciju, ali je ipak želela decu sa svojim novim mužem, jer je smatrala da ni u tim godima život udvoje bez dece nije potpun. Odlučila se za veštaćku oplodnju sa svojih 50 godina iako je već 2 godine u menopauzi, te su ciklusi ponovo pokrenuti, urađena je veštačka oplodnja koja je uspela već nakon prvog pokušaja i ona sada nosi blizance, dve devojčice.

Ovakvi primeri ukazuju na sasvim nov aspekt korišćenja savremenih tehnologija veštačke oplodnje i ukazuje da se one neće u budućnosti koristiti samo za lečenje neplodnosti već i kod žena koje se iz bilo kog razloga odluče da rađaju kasnije, čak i posle 50-te godine, možda u budućnosti i posle 60-te. Ovome svakako doprinosi činjenica da je Svetska zdravstevena organizacija (SZO) bebama rođenim 2014. godine prognozira životni vek od oko 94 godine. Zamrzavanje jajnih ćelija u njihovom najboljem periodu i njihovo kasnije korišćenje, kada žena to zaželi, uz razvoj embrionalnih matičnih ćelija (iz kojih se mogu dobiti i reproduktivne ćelije), omogućiće planiranje i ostvarivanje trudnoće u poznim ženskim godinama, koje će se sve više smatrati srednjim, najbol- 
jim godinama. Na takav način starije žene ili žene koje su iz bilo kog razloga izgubile reproduktivnu sposobnost, moći će da rađaju i bez donacije jajnih ćelija, već sa sopstvenim jajnim ćelijama, vitalnim i „mladim“, dobijenih iz matičnih ćelija. To je budućnost koja je pred nama. U naprednim društvima životni vek se rapidno produžava, te se na primer u Japanu oko 2050. godine očekuje broj od oko 1 milion stogodišnjaka. Toj rastućoj populaciji starih će svakako biti omogućena i reprodukcija u poznim godinama.
Ono što još nismo u stanju da predvidimo i što buduće studije tek treba da pokažu, jeste potencijalne udaljenje posledice na stanje zdravlja majki i dece iz ovakvih trudnoća, dakle globalni ishodi, obzirom da se radi o rastućem trendu koji se javlja poslednjih godina. Tek sa takvim rezultatima možemo dati završni kritički sud o grupi žena koje rađaju u poznim godinama života.

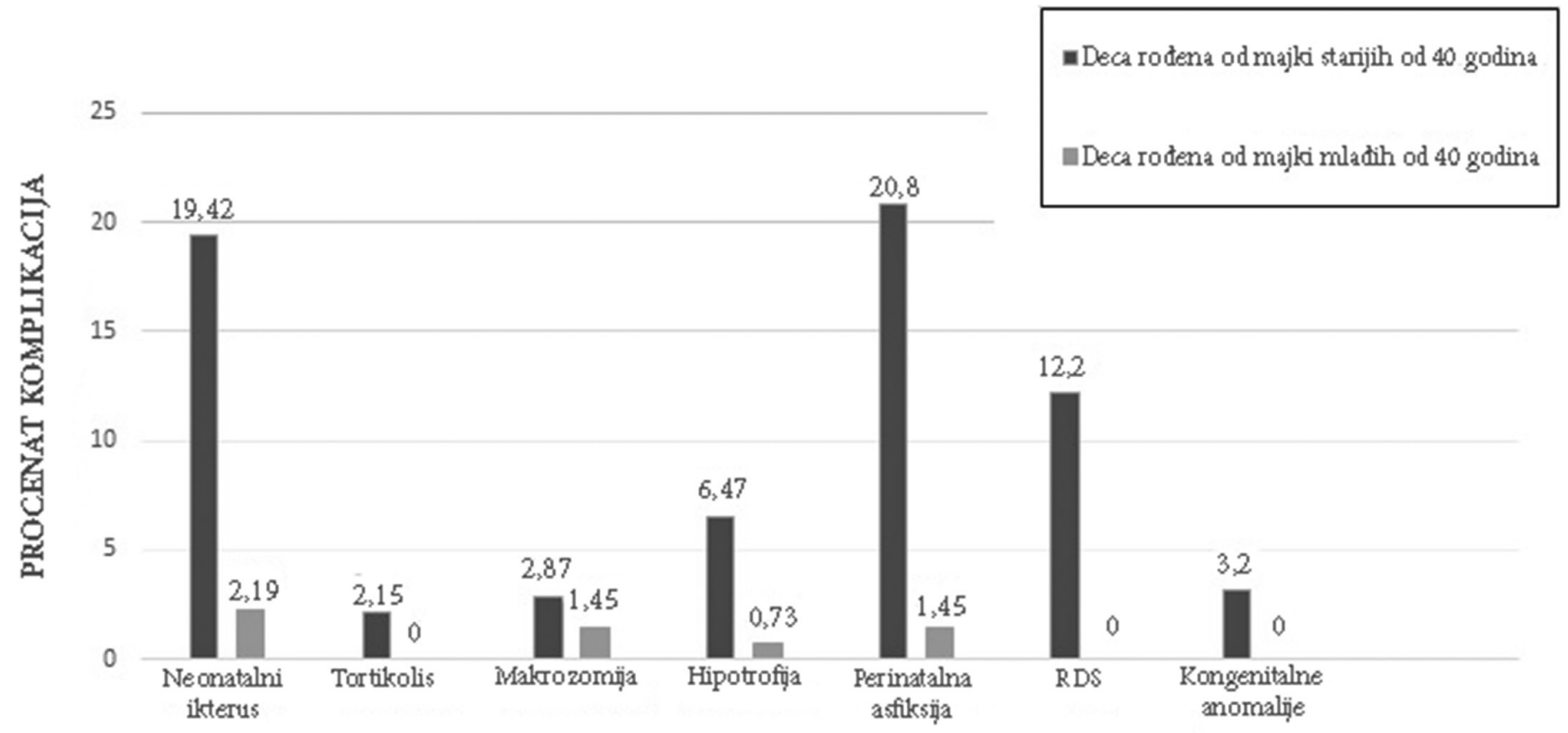

Grafik 4. Učestalost javljanja pojedinih stanja kod neonatusa iznetih iz trudnoća pacijentkinja starijih od 40 godina koje su zatrudnele asistiranim reproduktivnim tehnologijama na GAK Narodni Front u periodu od januara 2008. do decembra 2013. godine u poređenju sa istim komplikacijama kod neonatusa začetih prirodnim putem, kod majki mlađih od 40 godina $\mathrm{u}$ istom periodu.

\section{Literatura}

1. Eisenberg VH, Schenker JG. Pregnancy in the older woman: scientific and ethical aspects. International Journal of Gynecology and Obstetrics 1997;56:163-9.

2. Tough S, Tofflemire K, Benzies K, Fraser-Lee N, Newburn-Cook C. Factors influencing childbearing decisions and knowledge of perinatal risks among Canadian men and women. Matern Child Health J. 2007;11:189-98.

3. Sobotka T. Is lowest-low fertility in Europe explained by the postponement of childbearing? Popul Dev Rev. 2004;30:195-220.

4. Bergne'hr D. Timing parenthood: independence, family and ideals of life. Linkooping: Linkopings Universitet, 2008.

5. Gustafsson S, Kenjoh E, Wetzels C. The role of education in postponement of maternity in Britain, Germany, the Netherlands and Sweden. The gender dimension of social change: the contribution of dynamic research to the study of women's life courses. Bristol: The Policy Press, 2002. 20.

6. Benzies K, Tough S, Tofflemire K, Frick C, Faber A, Newburn-Cook C. Factors influencing women's decisions about timing of motherhood. J Obstet Gynecol Neonatal Nurs. 2006;35:625-33.

7. Bernhardt E, Goldscheider F. Gender equality, parenthood attitudes, and first births in Sweden. Vienna Yearbook of Population Research. 2006;4:19-39.

8. Mills M, Rindfuss RR, McDonald P, te Velde E, Reproduction obotE, Force ST. Why do people postpone parenthood? Reasons and social policy incentives. Hum Reprod Update. 2011;17:848-60.

9. Kahl H, Schaffrath Rosario A, Schlaud M. Sexual maturation of children and adolescents in Germany. Results of the German Health Interview and Examination Sur- 
vey for Children and Adolescents (KiGGS). Bundesgesundheitsblatt Gesundheitsforschung Gesundheitsschutz. 2007;50(5-6):677-85.

10. Laska-Mierzejewska T, Olszewska E. The maturation rate of girls living in rich and poor rural regions of Poland before and after the transformation of 1989. Homo. 2004;55(1-2):129-42.

11. Lu X, Lessner L, Carpenter DO. Association between hospital discharge rate for female breast cancer and residence in a zip code containing hazardous waste sites. Environ Res. 2014;134:375-81.

12. Navot D, Bergh PA, Williams MA, Garrisi JG, Guzman I, Sandler B, et al. Poor oocyte quality rather than implantation failure as a cause of age-related decline in female fertility. Lancet 1991;337:1375-7.

13. Borini A, Bianchi L, Violini F, Maccolini A, Cattoli M, Flamigni C. Oocyte donation program: pregnancy and implantation rates in women of different ages sharing oocytes from single donor. Fertil Steril 1996;65:94-97.

14. Meldrum DR. Female reproductive aging-ovarian and uterine factors. Fertil Steril 1993;59:1-5.

15. Chan BC, Lao TT. Influence of parity on the obstetric performance of mothers aged 40 years and above. Hum Reprod 1999;14(3):833-7.

16. Callaway LK, Lust K, McIntyre HD. Pregnancy outcomes in women of very advanced maternal age. Aust $\mathrm{N} Z \mathrm{~J} \mathrm{Ob}$ stet Gynaecol 2005;45(1):12-6.

17. Cunningham FG, MacDonald PC, Gant NF. Williams Obstetrics, 18th ed. Norwalk, CT: Appelton and Lange, 1989.

18. Kohn RR. Principles of Mammalian Aging, 2nd ed. Englewood Cliffs, NJ: Prentice-Hall, 1978.

19. Benshushan A, Schenker JG. Age limitation in human reproduction: is it justified? J Assist Reprod Genet 1993;10:321-331.

20. Flamigni C, Borini A. Counselling post-menopausal women for donor in-vitro fertilization and hormone replacement therapy. Hum Reprod 1995;10:1237-41.

21. MacLeod J, Gold RZ. The male factor in fertility and infertility. VII. Semen quality in relation to age and sexual activity. Fertil Steril 1953;4:194-207.

22. Jequier AM, Winterton WR. Diagnostic problems of trophoblast disease in women age 50 or more. Obstet Gynecol 1975;423:378-81.

23. Tuck SM, Yudkin PL, Turnbull AC. Pregnancy outcome in elderly primigravida with and without a history of infertility. Br J Obstet Gynaecol 1988;95:230-237.
24. Naeye RL. Maternal age, obstetric complications, and the outcome of pregnancy. Obstet Gynecol 1983;61:210-216.

25. Sibai B, Ross MG. Hypertension in gestational diabetes mellitus: pathophysiology and long-term consequences. J Matern Fetal Neonatal Med 2010;3:229-233.

26. Peipert JF, Bracken MB. Maternal age: an independent risk factor for cesarean delivery. Obstet Gynecol 1993;81:200205.

27. Irion O, Fournet Irion N. Pregnancy care in women older than 40 years and after egg donation. Rev Med Suisse. 2015;11(456-457):68-71.

28. Creasy RJ, Resnik R. Maternal Fetal Medicine Princi- ples and Practice, 2nd ed. Philadelphia: W.B. Saunders, 1989.

29. Friede A, Baldwin W, Rhodes PH, Buehler JW, Strauss LT. Older maternal age and infant mortality in the United States. Obstet Gynecol 1988;72:152-7.

30. Cnattingius S, Forman MR, Berendes HW, Isolate L. Delayed childbearing and risk of adverse perinatal out- come. J Am Med Assoc 1992; 268:886-90.

31. Frieman JM. Genetic disease in the offspring of older fathers. Obstet Gynecol 1981; 457: 75.

32. Vlatka Tomic, Jozo Tomic. Neonatal outcome of IVF singletons versus naturally conceived in women aged 35 years and over. Arch Gynecol Obstet 2011;284:1411-6.

33. Edwards RG. In vitro fertilization: past and future. Ann Biol Clin (Paris) 1987;45:321-9.

34. McDonald SD, Han Z, Mulla S, Murphy KE, Beyene J, Ohlsson A et al. Preterm birth and low birth weight among in vitro fertilization singletons: A systematic review and meta-analyses. European Journal of Obstetrics \& Gynecology and Reproductive Biology. 2009;146:138-48.

35. Centers for Disease Control and Prevention - 2013 Assisted Reproductive Technology National Summary Report Figures: Percentages of ART Cycles Using Fresh Nondonor Eggs or Embryos That Resulted in Pregnancies, Live Births, and Single-Infant Live Births, by Age of Woman,* 2013, available at: http://www.cdc.gov/art/pdf/2013-national-summary-slides/art_2013_graphs_and_charts_final_figure14.pdf

36. Centers for Disease Control and Prevention - 2013 Assisted Reproductive Technology National Summary Report Figures: Percentages of Embryos Transferred That Implanted Using Fresh Nondonor Eggs or Embryos, by Age Group, * 2013, available at: http://www.cdc.gov/art/pdf/2013-national-summary-slides/art_2013_graphs_and_charts_final_figure26.pdf 